Type of the Paper (Article)

\title{
Evaluation of Seasonal and Drought Conditions Effect on satellite-based Precipitation Data Accuracy over different Climatic Conditions
}

\author{
Salman Qureshi ${ }^{1}$, Javad Koohpayma ${ }^{2,}$, , Mohammad Karimi Firozjaei ${ }^{3}$, Ata Abdollahi Kakroodi ${ }^{4}$ \\ 1 Institute of Geography (Landscape Ecology), Humboldt University of Berlin, Rudower Chaussee 16, \\ 12489 Berlin, Germany; salman.qureshi@geo.hu-berlin.de \\ 2 Department of Remote Sensing and G.I.S., Faculty of Geography, University of Tehran, Tehran 14178- \\ 53933, Iran; javad.koohpayma@ut.ac.ir \\ 3 Department of Remote Sensing and G.I.S., Faculty of Geography, University of Tehran, Tehran 14178- \\ 53933, Iran; mohammad.karimi.f@ut.ac.ir \\ 4 Department of Remote Sensing and G.I.S., Faculty of Geography, University of Tehran, Tehran 14178- \\ 53933, Iran; a.a.kakroodi@ut.ac.ir \\ * Correspondence: javad.koohpayma@ut.ac.ir; Tel.: +98-9330989001
}

\begin{abstract}
The Tropical Rainfall Measuring Mission (TRMM) and then Global Precipitation Mission (GPM) are the most important and widely used data sources in the forecasting of drought, flood, and water resources management. However, since this sensor's data is primarily used for tropical regions, it is necessary to evaluate the accuracy for optimal use of the data across varying climatic and physiographic conditions. In this study, the accuracy of the satellite data for a span of 17 years (2000-2017) for three climatic zones has been explored using synoptic ground station data. The climates include a) arid and low rainfall, b) semi-arid and low rainfall, and c) humid and high rainfall. We evaluated satellite data accuracy in drought and wet conditions based on the Standard Precipitation Index (S.P.I.) and different seasons. For available ground control stations, 13 stations were used in the humid, seven stations in a semi-arid climate, and 12 stations in the dry climate. The results show that the monthly precipitation product of GPM (IMERG product) and TRMM (TMPA/3B43 product) overestimate the rainfall. In the arid climate, the precipitation is estimated $43 \%$, in the semi-arid environment $50 \%$, and in the humid weather $11 \%$ more than the ground-based data on average. Therefore, to use satellite data in different climates, it is necessary to make corrections to obtain precise results. Based on 32 ground stations, the correction coefficient has a positive relationship with average precipitation and altitude and an inverse relationship with the latitude. Further in-depth investigations showed that the accuracy of satellite data in wet conditions is higher than the accuracy of normal circumstances, and the accuracy of normal conditions is more accurate than drought conditions. Besides, the accuracy of satellite data in wet or dry conditions increases with increasing time scales. The highest accuracy was obtained for a 12-month time scale and the lowest accuracy for the 3-month time scale of drought conditions in the arid climate.
\end{abstract}

Keywords: Satellite precipitation; TRMM and GPM; Correction factor; S.P.I.; Different climates; rainfall precision

\section{Introduction}

Water is a major part of a country's economic and social development, and rain is the principal source of freshwater on the Earth. Efficient management in this field needs accurate and precise information on precipitation and its temporal-spatial variations [1]. On the other hand, rain is the main factor in the water cycle and the balance of the Earth's energy [2] and directly impacts climate change [3]. Precipitation data is used in many areas, such as flood forecasting [4], landslides [5], heavy rain forecast [6], water resources management [7], Drought Monitoring [8], Hydrological Modeling [9], Meteorological Applications [10, 11], and Improving Agriculture yield estimation and Soil Moisture [12]. 
Ground observations are the most accurate source of available information, but the non-uniform distribution and the lack of rainfall gauges, roughness, and topography limit their application and make it difficult to study large areas. As a result, local variations pattern is not accurately extracted [13]. Although interpolation techniques can estimate the quantity of precipitation, the results contain high uncertainty, especially in areas with a small number of gauges. Besides, some meteorological stations are newly established; therefore, they only cover short periods. As a result, it is not possible to process data for longer ranges.

Satellite precipitation data have a wide range, and since 1998, they are freely available and have covered almost the entire globe continuously except high latitudes. The products now have global coverage and is a valuable resource of rainfall data in different parts of the world without spatial limitations. Satellite data also has the advantage over ground-based data that its distribution is homogeneous and provides continuous precipitation information both spatially and temporally so that it is accessible even to remote regions and saves money and time. However, the provided data have drawbacks and inaccuracies in some areas due to limitations in algorithms and satellite tools [14-17]. Accurate precipitation data is essential and also plays a fundamental role in water resources management. For example, the amount of rainfall required for each agricultural crop varies. The required rainfall is defined as the amount of water directly and indirectly needed for plant growth [18]. The accurate estimation of precipitation directly impacts water resources management to create a balance between the amount of required water and precipitation. Besides, the accuracy of precipitation is crucial for monitoring and forecasting drought and has many applications in agriculture and flood forecasting $[19,20]$. Studies on the satellite precipitation data show that they have different accuracies in different climates [7]. For example, Adeyewa and Nakamura [21] showed that their accuracy varies in dry, semi-dry, savannah, and tropical climates in Africa. These issues limit the use of this data resource and may lead to incorrect results in some areas.

In recent years, due to global warming issues, drought-related studies have attracted decision-makers. Drought is usually a condition of moisture deficit that occurs due to a lack of precipitation over a while $[22,23]$. Drought occurs almost anywhere in the world, even in rainy regions [24], and can last from a few months to several years, causing enormous damage to the economy and society [25]. Different indicators are used to diagnose drought and wet conditions [26]. However, many studies [27-31] have shown that the Standardized Precipitation Index (S.P.I.) can be used well for different climates in Iran to assess the frequency and duration of droughts. The index, developed by McKee, Doesken [22], describes the cumulative probability of precipitation at any given period. Also, this index only requires rainfall data and therefore has fewer calculations. In this study, we utilized the S.P.I. index to evaluate the accuracies of satellite precipitation products, including Global Precipitation Measurement (GPM) and Tropical Rainfall Measuring Mission (TRMM) in drought and wet conditions.

GPM was launched in 2014 to continue collecting rainfall data after completing the TRMM mission in 2015. Product 3B43 of TRMM and IMERG product of GPM provide monthly precipitation in millimeters per hour in $0.25^{\circ} \times 0.25^{\circ}$ and $0.1^{\circ} \times 0.1^{\circ}$ resolutions, respectively. Several studies have been conducted on their accuracies [32-34] in the world and the country Iran. Sharifi, Steinacker [35] compared the daily data of ground gauges and GPM data in different climatic conditions and seasons over Iran. However, their work was limited to only the years 2014 and 2015. They concluded that GPM was superior to the TRMM. Also, they found that monthly products underestimated the precipitation in high rain climatic conditions. However, in arid and semi-arid conditions, GPM and TRMM overestimated the rainfall data. Maghsood, Hashemi [36] used multiple statistical indexes to compare daily and monthly products of GPM and TRMM all over the country for the period 2014-2017. They resulted in the same conclusions. In this study, not only we compared assessed the satellite data for a long period (2000-2017), but also, we used ground station precipitation data to measure the drought and wet conditions to evaluate the GPM/TRMM data in the corresponding conditions. The satellite data have 
been used for drought monitoring by many researchers [37-39] over the globe. However, to our knowledge, no study compared the accuracy of satellite data itself in drought and wet circumstances. In this study, we evaluated the seasonal and drought conditions effect on satellite-based precipitation data accuracy over different Climatic Conditions. Also, we examined the relationship between the precision of satellite data with ground metrological station positions and the amount of rainfall to predict the precision of the GPM/TRMM data.

\section{Materials and Methods}

\subsection{Study area}

The study area includes three provinces in the North, North-East, and South-East Iran, each with a different climatic condition. Figure 1 shows the study areas and average precipitation of the country using GPM data from 2000 until the end of 2017.

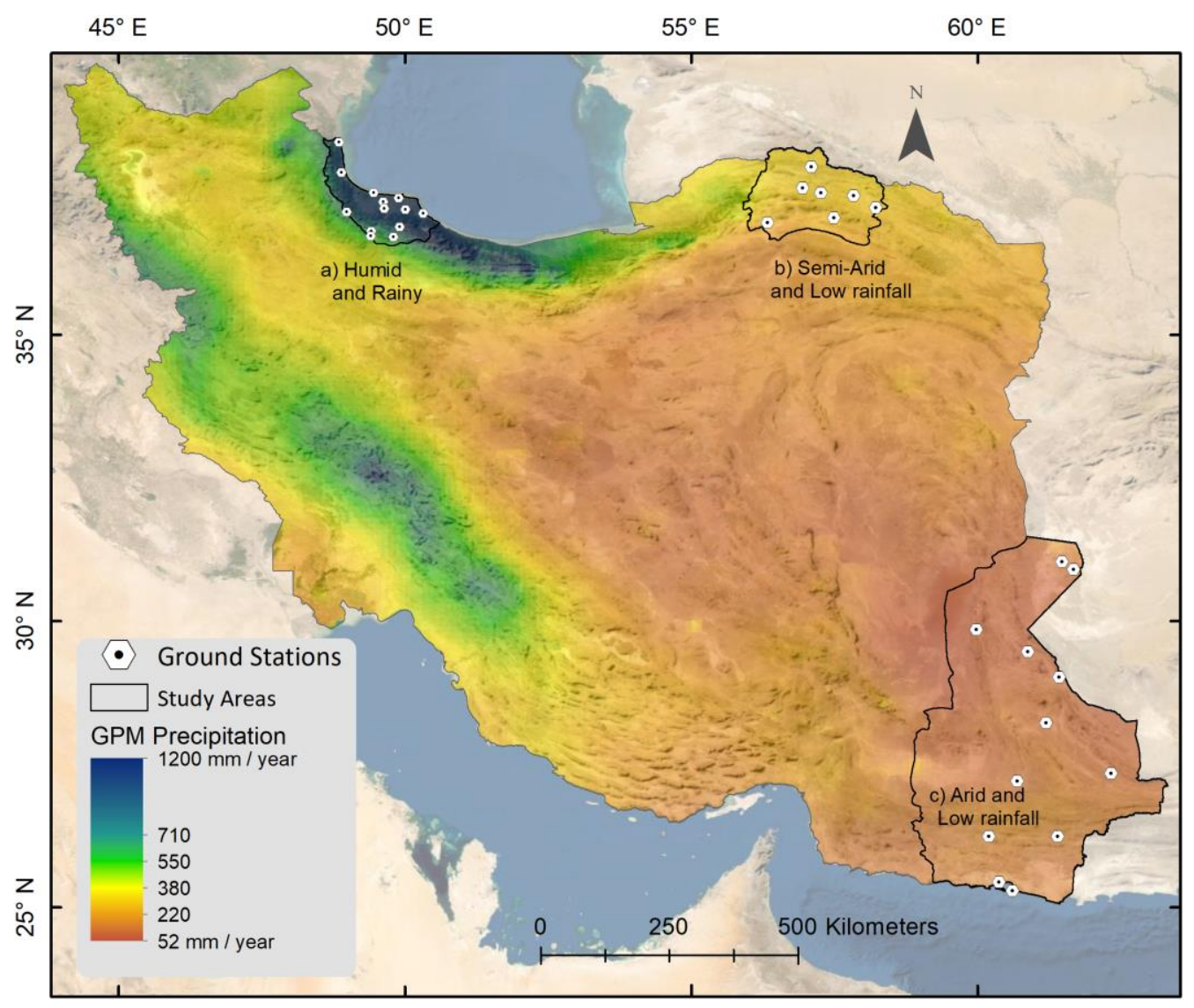

Figure 1. The study area a) humid and rainy b) semi-arid and low rainfall c) arid and low rainfall.

\subsubsection{Gilan Province (Humid and High Rainfall)}

Gilan province is located in the North of Iran on the Southside of the Caspian Sea, between latitude 36.5 to 38.5 degrees and longitude 58.5 to 50.5 degrees (Area 'a' in Figure 1 ). It covers an area of 14,711 square kilometers and $0.9 \%$ of the country's total area. It is located between the Alborz mountain chains that have separated the area from the rest of Iran and the Caspian Sea. Alborz mountains, with an average height of 3000 meters, cover the plain of Gilan, and this factor has caused the greenery of the province. Alborz plays as an impenetrable wall that blocks water vapor of the Caspian Sea and Northern winds into the Southern regions. Because of this reason, Gilan is the rainiest region of Iran. The average annual rainfall of the province is $1270 \mathrm{~mm}$, while the average rainfall in the whole country is $255 \mathrm{~mm}$. One-third of the province is covered with forests, with an estimated area of 51,1306 hectares. Due to the suitable climate, moist, fertile soil, and the 
existence of a permanent running water network, it has a high population density, which is the second-most populous province in the country after Tehran province $[41,40]$.

\subsubsection{North Khorasan Province (Semi-Arid and Low Rainfall)}

The province's area is 28179 square kilometers located in the North-East of the country, between latitude 36.5 to 38.3 degrees and longitude 55.8 to 58.4 degrees (Area ' $b$ ' in Figure 1). The average altitude of this area is 1326 meters, the highest point is 3051 meters, and the lowest altitude is 400 meters above sea level. The North of the province includes the Kopeh-Dagh mountain chain, which reaches the Alborz mountain chain by low mountains. The climate of this region is semi-arid, the average annual temperature is 13 degrees Celsius, and the maximum temperature in summer reaches 40 degrees Celsius. The average yearly rainfall in the region is $230 \mathrm{~mm}$, with the highest rainfall of 468 $\mathrm{mm}$ and the lowest of $120 \mathrm{~mm}[43,42]$.

\subsubsection{Sistan-Baluchestan Province (Arid and Low Rainfall)}

The province is located in South-East of Iran between 25.06 and 31.50 degrees latitude and 58.75 to 63.32 degrees longitude (Area ' $c$ ' in Figure 1). With an area of 180,726 square kilometers covers about 11 percent of Iran's area. The Northern part of the province has an average altitude of 475 meters above sea level, adjacent to the Lut Desert. But the Southern part is a large mountainous area that reaches the Oman Sea. The climate of this province is mostly hot and dry, although it also has mountainous, forested, and wetland areas. The average precipitation in the area is $95 \mathrm{~mm}$ per year, with a maximum of $130 \mathrm{~mm}$. Only 400,000 hectares of the province is suitable for cultivation. The maximum temperature of the province during the study period has reached 52 degrees Celsius. Due to low rainfall and snow resources, most of the province's rivers are seasonal and temporary; therefore, groundwaters are the province's water supply $[45,44]$.

Figure 2 shows the annual averages of relative humidity, Sunny hours, temperature, precipitation, and ground stations' altitude in the study areas in one graph. The parameters have been scaled to display stations' characteristics in a single graph.

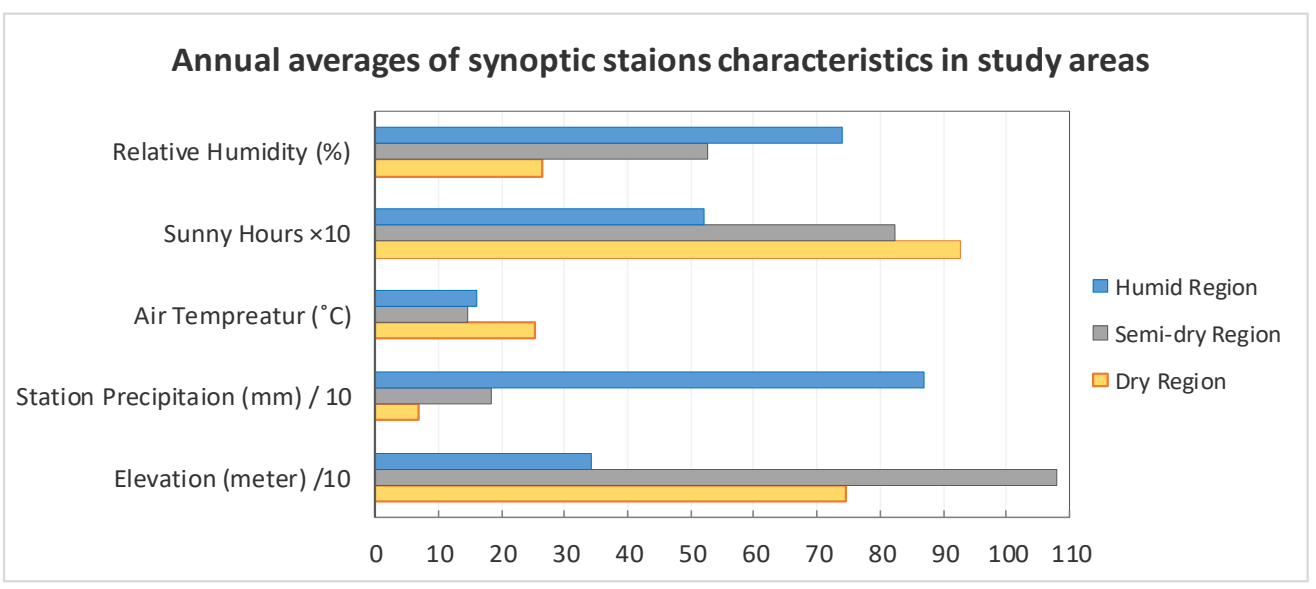

Figure 2. Annual average of relative humidity, sunny hours, air temperature, precipitation., and elevation in the study areas

\subsection{Dataset}

2.2.1. Basic data 
In this study, the synoptic ground stations dataset was considered as reference data. These data were obtained from the Meteorology Organization of Iran. Gilan, North Khorasan, and Sistan-Baluchestan provinces include 13, 7, and 12 synoptic ground stations, respectively. For all stations, the lowest rainfall and sunny hours are zero, and the highest amount of relative humidity is 100\%.

\subsection{2. satellite-based data}

The Tropical Rainfall Measuring Mission (TRMM) was a joint project between the Japan Aerospace Exploration Agency (JAXA) and NASA, which measured precipitation data from 1998 to 2015. The TRMM satellite operates in an orbit of $350 \mathrm{~km}$ above the Earth's surface, and its products cover latitudes between 50 degrees North and South. Following the successful completion of TRMM in 2015, the project was continued by Global Precipitation Measurement (GPM). In addition to measuring rainfall, GPM can record snowfall and rainfall of less than $0.5 \mathrm{~mm}$ per hour. GPM is also capable of covering latitudes between $65^{\circ}$ in the North and South.

Satellite precipitation data of TRMM product TMPA/3B43 Version 7 (Although TRMM discontinued, the TMPA products is continued using other satellites in the constellation) and the Integrated Multi-satellitE Retrievals for GPM product (IMERG Level 3) were obtained from the NASA website (https://pmm.nasa.gov/data-access/downloads/trmm) and (https://pmm.nasa.gov/data-access/downloads/gpm) respectively for the 2000-2017 period. Then precipitation data were extracted at ground stations' locations. TRMM has data since 1998 but GPM (IMERG product) since 2000; therefore, we selected the period from 2000 to 2017.

\subsection{Technical framework}

In this study, we pursue two objectives. The first aim is to compare the accuracy of the satellite precipitation data based on ground station measurements over the study time range, drought conditions, and seasons. The second objective is to find a coefficient that minimizes the Root Mean Square Error (RMSE).

\subsection{Accuracy and Precision assessment of satellite data on the synoptic ground stations}

The accuracy of satellite data was compared using scatter plots between ground stations and corresponding satellite image pixels. The Pearson correlation coefficient was calculated for each dataset to measure the accuracy of satellite data. Also, we introduced the following equation so that $\mathrm{x}$ is the factor that should be calculated, whereas it makes the equation minimum based on the ground stations and their corresponding satellite data. By minimizing the following equation, the best coefficients for approaching precise rainfall values from two sources are achievable.

$$
R M S E=\sqrt{\frac{\sum(x \times \text { GPM or TRMM }- \text { Station })^{2}}{N}}
$$

In Equation 1, $\mathrm{x}$ is a factor that must be multiplied by the average monthly rainfall of GPM/TRMM. By changing it, the smallest RMSE can be obtained, and N is the number of records. If the $\mathrm{x}$-factor is higher than one, it means the stations' values are more prominent than GPM/TRMM values, and GPM/TRMM underestimates the data. If the $x$ value is less than one, the GPM/TRMM overestimates the rainfall data. $X$, which hereafter is called correction factor (C.F.), controls the peaks, which may be an important factor in flood occurrences.

\subsection{Accuracy assessment of satellite data over drought and wet conditions}

Despite the acceptable spatial and temporal coverage of TRMM and GPM data (since 1998) and its extensive use in modeling, it has limitations due to the need for 
complex algorithms. On the other hand, the values presented in high latitudes and areas with severe convection currents have higher values than the actual ones (Huffman et al., 2019) [45]. In this study, we compared the Accuracy of TRMM data in different climatic regions, including low rainfall, semi-dry low rainfall, and dry areas during drought and wet conditions periods. We used the S.P.I. index to determine these periods because the index can be used in any climate type, and its calculation needs only precipitation data.

\subsubsection{S.P.I. index}

The Standard Precipitation Index (S.P.I.) is widely used in meteorological drought studies over different periods [46, 47]. Lack of rainfall in the short term affects soil moisture, while in the long periods, it often affects groundwater, river flow, and water resources [47-49]. Therefore, in short periods, S.P.I. indicates soil moisture, and in more extended periods, S.P.I. is related to the amount of groundwater reserves. Also, this indicator can be used to compare the climates that are significantly different.

The steps of S.P.I. calculation are as follows. A probability function is first determined that indicates the time series of precipitation observations to obtain the S.P.I. value. Then, the probability of the value of an observation is calculated. Finally, the inverse normal function (Gaussian) is applied with an average of zero and a variance on the cumulative probability, which results in S.P.I. [47]. This time series can be done for any desired period, such as one, three, six, 12, and 24 months. The value of the S.P.I. is obtained from equation 2, in which the S.P.I. is the standardized precipitation index, $\mathrm{f}(\mathrm{P})$ is the sum of the converted precipitation, $\mu$ is the mean of the normalized amount of rainfall, and $\delta$ is the standard deviation of the normalized precipitation.

$$
S P I=\frac{f(P)-\mu}{\delta}
$$

Table 1 shows the threshold values for the S.P.I. for determining drought and wet periods. We classified the precipitation data of the ground stations according to this table, and then the correlation between them and satellite data was examined.

Table 1. Classes of drought and wet conditions based on S.P.I.

\begin{tabular}{cc}
\hline Period & S.P.I. \\
\hline Extremely wet & $\geq+2.0$ \\
Very wet & +1.5 to +1.99 \\
Moderately wet & +1.0 to +1.49 \\
Normal & +0.99 to -0.99 \\
Moderately dry & -1.0 to -1.49 \\
Very dry & -1.5 to -1.99 \\
Extremely dry & $\leq-2.0$ \\
\hline
\end{tabular}

\subsection{Seasonal accuracy of satellite dataset}

The amount of rainfall and its importance vary from season to season over a year. For example, winter rains have a more significant impact on forest health. The tree rings indicate rains in the cold seasons; in other words, trees have the highest growth in the years with rainy winters, and tree patterns can be traced back to winter rainfall patterns [50]. Also, the lack of rainfall in winter and spring causes the forests to become more vulnerable to fire and the fire season to start sooner [51]. However, in the summer, rainwater quickly enters the rivers, and the remaining moisture evaporates quickly in the summer sun [52]. Because of these reasons, satellite data in these areas were separated according to seasons (Table 2), and their accuracies were assessed based on different seasons. 
Table 2. Seasons are divided according to the months of the year.

\begin{tabular}{cc}
\hline Season & Months \\
\hline Spring & March, April, May \\
Summer & Jun, July, August \\
Autumn & September, October, November \\
Winter & December, January, February \\
\hline
\end{tabular}

\subsection{Linear regression to predict the satellite data precision}

Regression means predicting and displaying changes in one variable based on information from another variable. Regression analysis is one of the most important statistical analyzes and one of the most widely used methods in estimating the changes of a dependent variable based on independent variables. Therefore, existing relationships can be extracted, examined, and modeled by these analyses, and the reasons behind the patterns can be discovered. It is also possible to gain a better understanding of them and make predictions based on them [53]. The aim of linear regression is a line that has the most fits the data. Ordinary least squares estimation is a linear regression method that selects values for parameters so that the mean square error (M.S.E.) is minimized [54]. Based on the synoptic ground stations and the values of the corresponding correction factors, we established the following linear regression equation.

$$
X=\alpha_{0}+\sum_{i=1}^{n} \alpha_{i} V_{i}
$$

In equation $3, \mathrm{X}$ is the correction coefficient, $\alpha$ is a coefficient, and $\mathrm{V}$ represents station parameters. We used the stepwise method to find statistically significant independent variables.

\section{Results}

\subsection{Accuracy and precision of Satellite data over the study areas}

Figure 3 shows the comparison of precipitation based on satellite and station for the studied provinces' centers with different climatic conditions. The precipitation data are measured in millimeters per hour; we displayed only three stations. In all graphs, GPM shows more accuracy than TRMM. As shown in graphs, GPM is better than TRMM, especially in low rainfall, which the accuracy of GPM is more than $30 \%$ higher than TRMM. In the high rain region (a), the higher the rainfall, the larger the errors. 

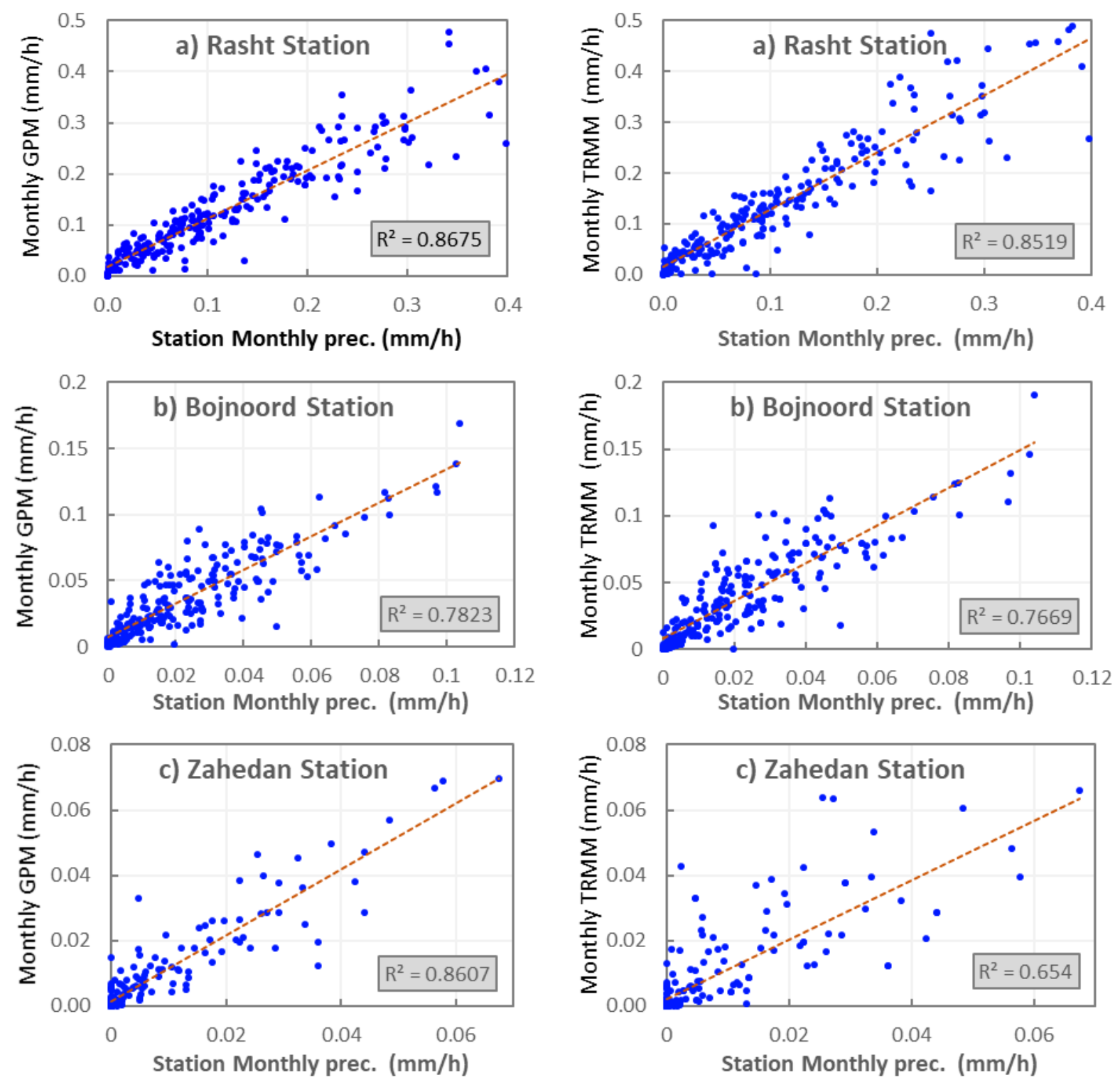

Figure 3. Comparison of monthly average precipitation between stations and satellite (TRMM and GPM) a) Rasht city (Humid) b) Bojnoord city (Semi-Arid) c) Zahedan city (Arid)

Figure 4 illustrates monthly variations of stations, GPM, and TRMM precipitation of a ground station as an example. Only five years were selected for better visualization. As shown in the graphs, the GPM and TRMM overestimate the rainfall data of the station, especially in the peaks. The patterns of corrected data are as same as the original ones. They are more compatible with ground station data patterns than not corrected data. Whereas the correction factor simply multiplied to the GPM/TRMM, so it does not change the zero points. Also, the higher the amount of quantity, the larger the effect of the correction factor on the data. 

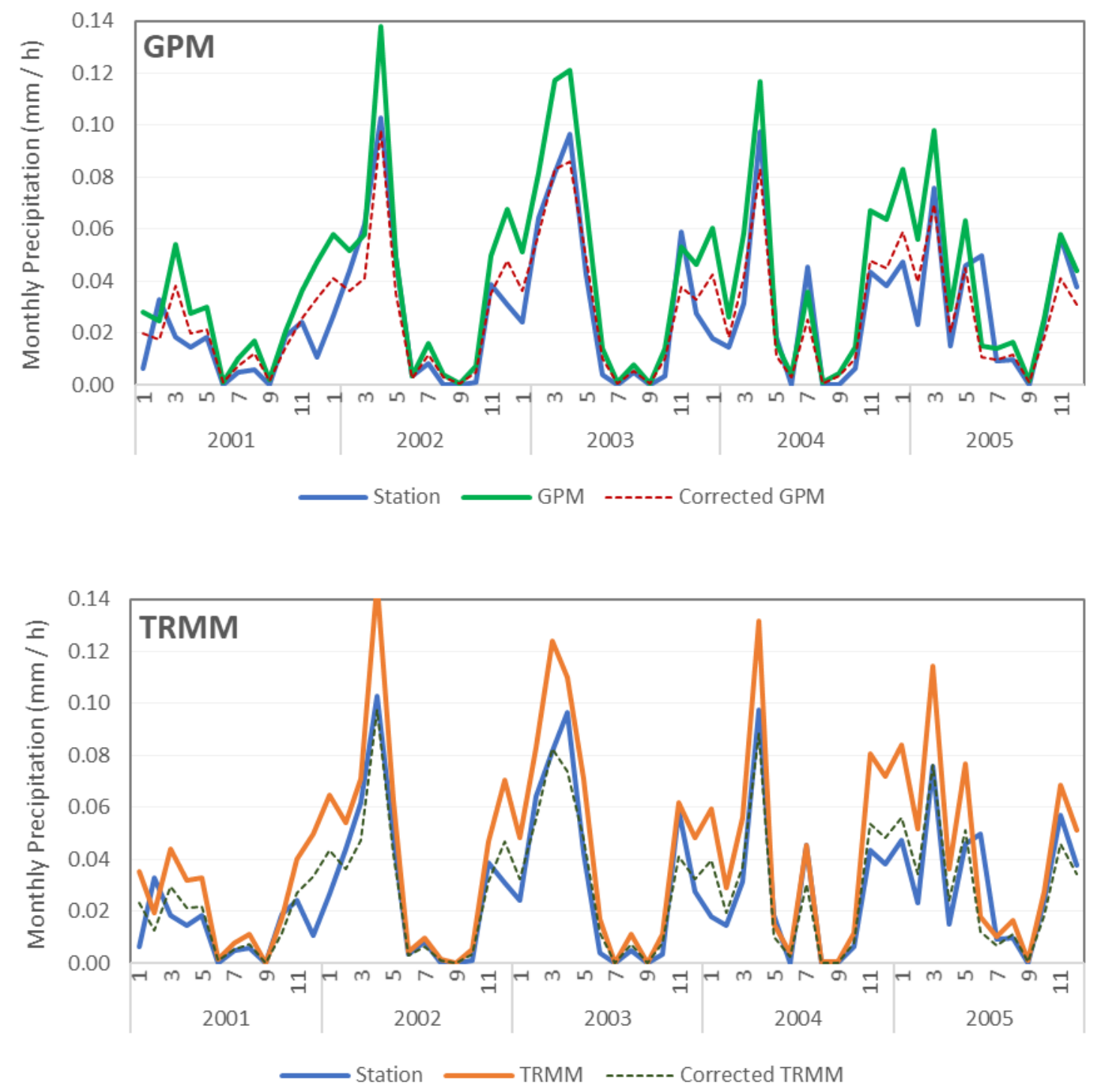

Figure 4. Comparison of monthly precipitation change graphs of ground Station, GPM, TRMM, and corrected data from 2001 to 2005 for Bojnoord city in semi-arid and low rainfall - The satellite data overestimates the rainfall.

The accuracy and correction factors (XGPM and XTRMM) of all ground stations are listed in Table 3. The GPM/TRMM data overestimates the precipitation data because the C.F. is less than one. It means the satellite data should be decreased. However, in high rain region, GPM/TRMM mostly underestimates the precipitation. As can be seen, not only is GPM more accurate than TRMM; but also, it is more precise than TRMM. On average, GPM has the highest accuracy in the arid region but TRMM in high rain areas. The highest discrepancy between GPM and TRMM accuracy happened in ZAHAK, which is bolded.

Table 3. Accuracy and correction factors of GPM and TRMM in-ground stations 


\begin{tabular}{|c|c|c|c|c|}
\hline Station & $\mathbf{R}^{2} \mathrm{GPM}$ & $\mathbf{R}^{2}$ TRMM & $\overline{X_{\mathrm{GPM}}}$ & $\mathbf{X}_{\text {TRMM }}$ \\
\hline Astara & 0.74 & 0.73 & 1.27 & 1.29 \\
\hline Anzali & 0.76 & 0.76 & 1.29 & 1.20 \\
\hline Talesh & 0.59 & 0.46 & 0.96 & 1.01 \\
\hline Deylaman & 0.54 & 0.53 & 0.38 & 0.48 \\
\hline Rasht (Airport) & 0.86 & 0.83 & 0.95 & 0.79 \\
\hline Rasht (Agri.) & 0.83 & 0.77 & 0.99 & 0.94 \\
\hline Rood Bar & 0.25 & 0.30 & 0.36 & 0.40 \\
\hline Rood Sar & 0.66 & 0.73 & 1.11 & 1.16 \\
\hline Kiashahr & 0.72 & 0.68 & 0.99 & 0.86 \\
\hline Lahijan & 0.77 & 0.76 & 1.21 & 1.20 \\
\hline Masoole & 0.77 & 0.66 & 0.98 & 1.05 \\
\hline Manjil & 0.50 & 0.57 & 0.29 & 0.39 \\
\hline Average & 0.67 & 0.65 & 0.90 & 0.90 \\
\hline StdDev & 0.17 & 0.16 & 0.36 & 0.32 \\
\hline Esferain & 0.71 & 0.67 & 0.64 & 0.57 \\
\hline Bojnoord & 0.74 & 0.72 & 0.65 & 0.57 \\
\hline Jajrom & 0.54 & 0.45 & 0.47 & 0.51 \\
\hline Raz & 0.68 & 0.67 & 0.71 & 0.85 \\
\hline Shirvan & 0.84 & 0.75 & 0.59 & 0.56 \\
\hline Farooj & 0.94 & 0.92 & 0.76 & 0.71 \\
\hline Ashkhaneh & 0.76 & 0.71 & 0.94 & 0.78 \\
\hline Average & 0.75 & 0.70 & 0.68 & 0.65 \\
\hline StdDev & 0.12 & 0.14 & 0.15 & 0.13 \\
\hline Khash & 0.74 & 0.59 & 0.60 & 0.60 \\
\hline Rask & 0.88 & 0.78 & 0.71 & 0.66 \\
\hline Zabul & 0.90 & 0.81 & 1.25 & 1.15 \\
\hline Zahedan & 0.68 & 0.58 & 0.83 & 0.74 \\
\hline Zahak & 0.85 & 0.15 & 0.43 & 0.05 \\
\hline Saravan & 0.90 & 0.70 & 0.79 & 0.70 \\
\hline $\begin{array}{l}\text { Konarak (Air- } \\
\text { port) }\end{array}$ & 0.80 & 0.63 & 0.46 & 0.43 \\
\hline MirJave & 0.77 & 0.83 & 0.73 & 0.86 \\
\hline NosratAbad & 0.69 & 0.47 & 0.69 & 0.91 \\
\hline NikShahr & 0.75 & 0.63 & 0.48 & 0.48 \\
\hline Chabahar & 0.68 & 0.50 & 0.89 & 0.76 \\
\hline IranShahr & 0.70 & 0.69 & 0.78 & 0.81 \\
\hline Average & 0.78 & 0.61 & 0.72 & 0.68 \\
\hline StdDev & 0.09 & 0.18 & 0.23 & 0.28 \\
\hline
\end{tabular}

Figure 5, Figure 6, and Figure 7 demonstrate the values of corrections factors for both data sets in the study areas. In the mentioned figures, the satellite images are tilted to be visualized as 3D images. In each station, GPM and TRMM are compared with station precipitation measurement. In ideal, satellite data is equal to ground station data. However, satellite data overestimate and underestimate the actual data. The larger the data, the larger the space occupied in the circles. 


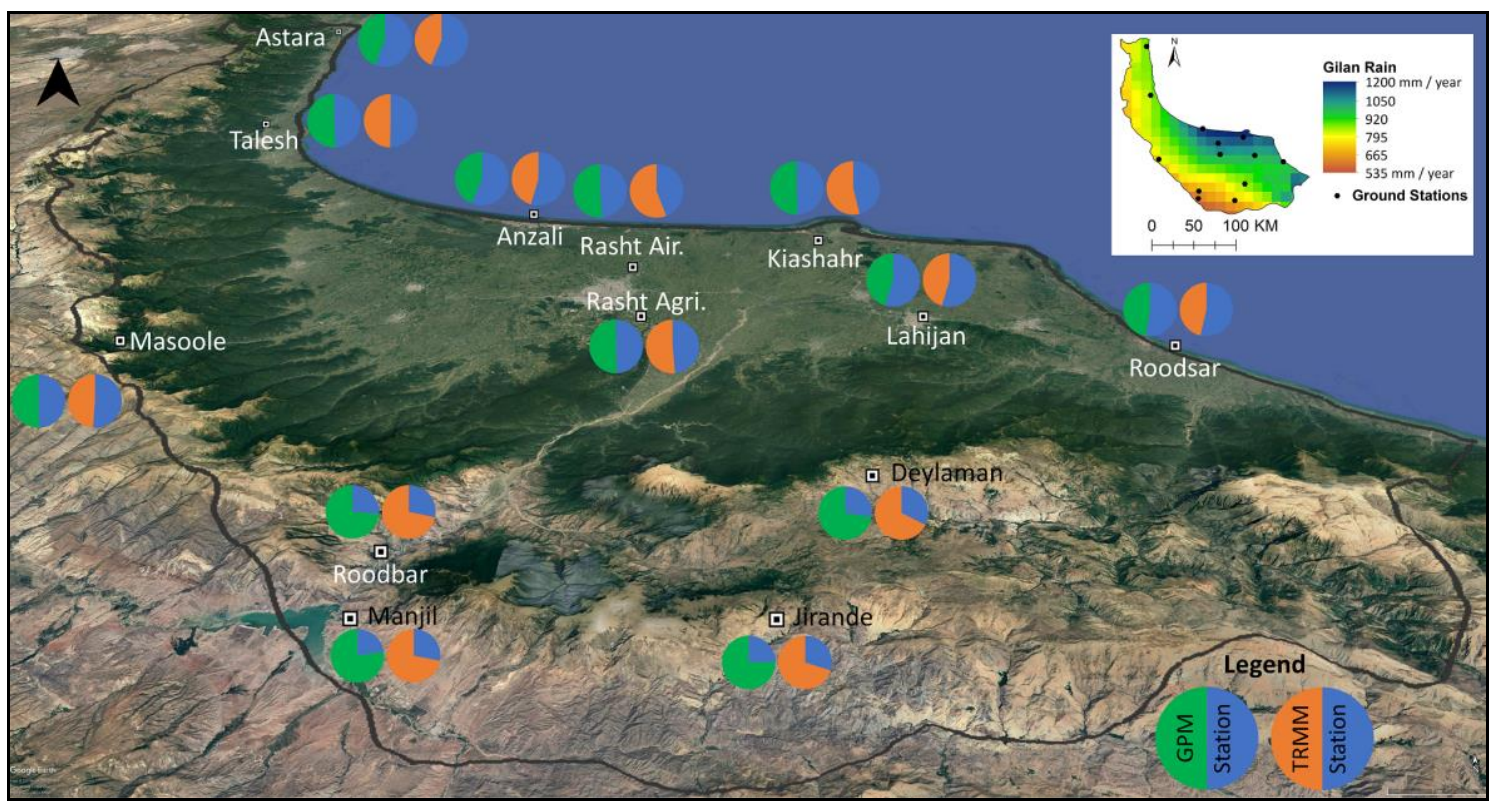

Figure 5. Rain correction coefficient for provinces a) Gilan. The legend is shown when TRMM and Station have an equal amount; in most stations, TRMM's amount is more than the station.

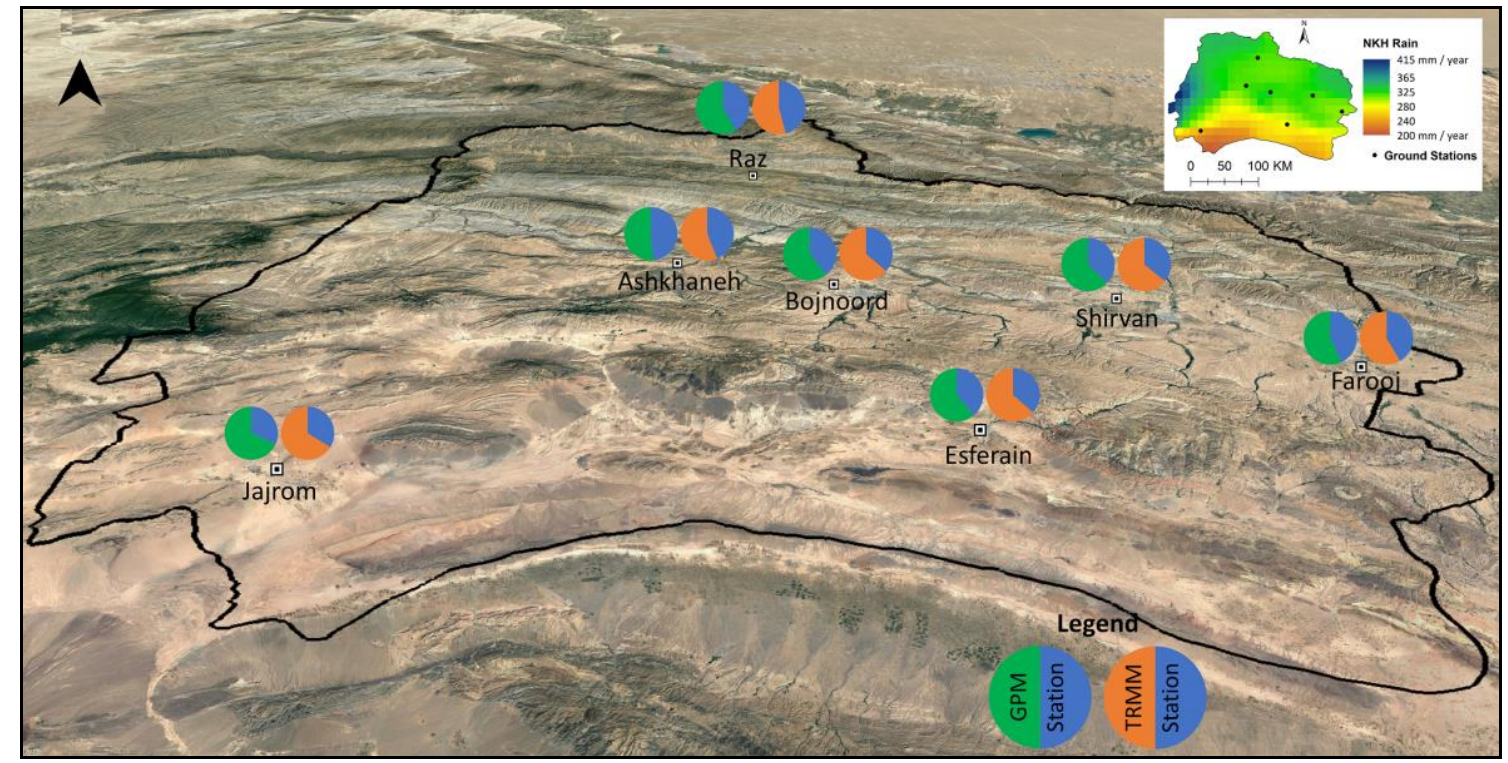

Figure 6. Rain correction coefficient for provinces b) North Khorasan. The legend is shown when TRMM and Station have an equal amount; in most stations, TRMM's amount is more than the station. 


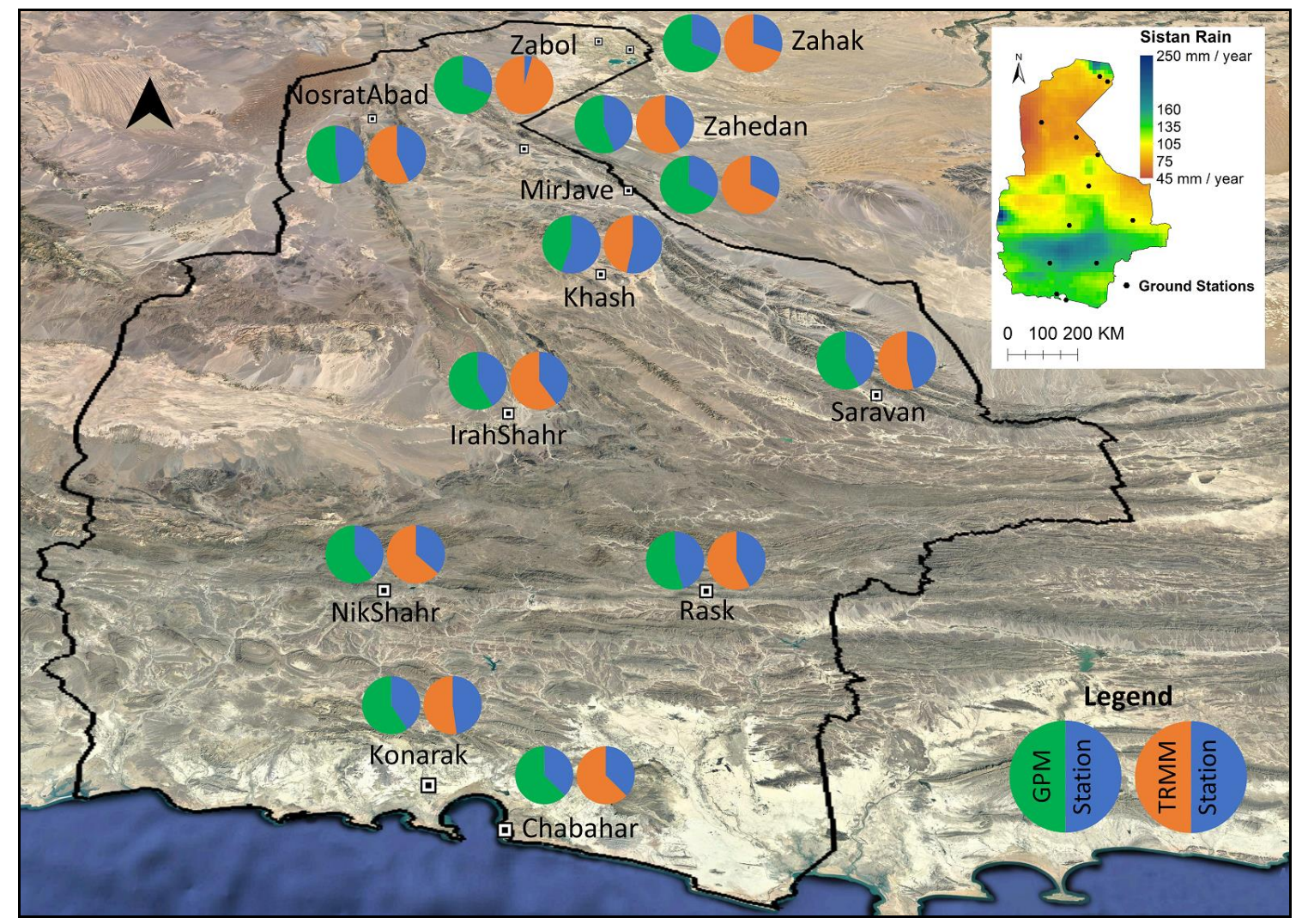

Figure 7. Rain correction coefficient for provinces c) Sistan-Baluchestan. The legend is shown when TRMM and Station have an equal amount; in most stations, TRMM's amount is more than the station.

\subsection{Accuracy of GPM and TRMM data in wet, normal, and drought periods}

Using the S.P.I. thresholds shown in Table 1, drought and wet conditions can be identified at each station. Since S.P.I. takes at least 20 years of data, it was calculated for stations with data all over the period from1998 to 2017. Figure 8 shows the results of comparing ground data with satellite data for different study areas under different drought conditions. Three- and six-month intervals were considered for a short-term period, and 12- and 24-month periods for a long-term period. The R2 factor shows the percentage of variation in the amount of ground station rainfall explained by satellite data.

As can be seen, in the humid climatic condition, the accuracy of satellite data on a short-term scale ( 3 and 6-month) are 0.48 and 0.46 for GPM and TRMM, respectively. In comparison, their accuracies during the corresponding wet condition are 0.80 and 0.82 . There is the same pattern with a lower discrepancy in the semi-arid region. In the arid region, the $\mathrm{R}^{2}$ factor of GPM in the 3-month S.P.I. scale increased from 0.35 to 0.9 and TRMM from 0.25 to 0.77 .

The improvement of accuracy from GPM to TRMM is considerable in arid climatic conditions. The overall $\mathrm{R}^{2}$ factor in the mentioned region is 0.86 for GPM, while for TRMM is 0.64 . The overall enhancement of accuracy is only two percent in the humid and semi-arid regions. 

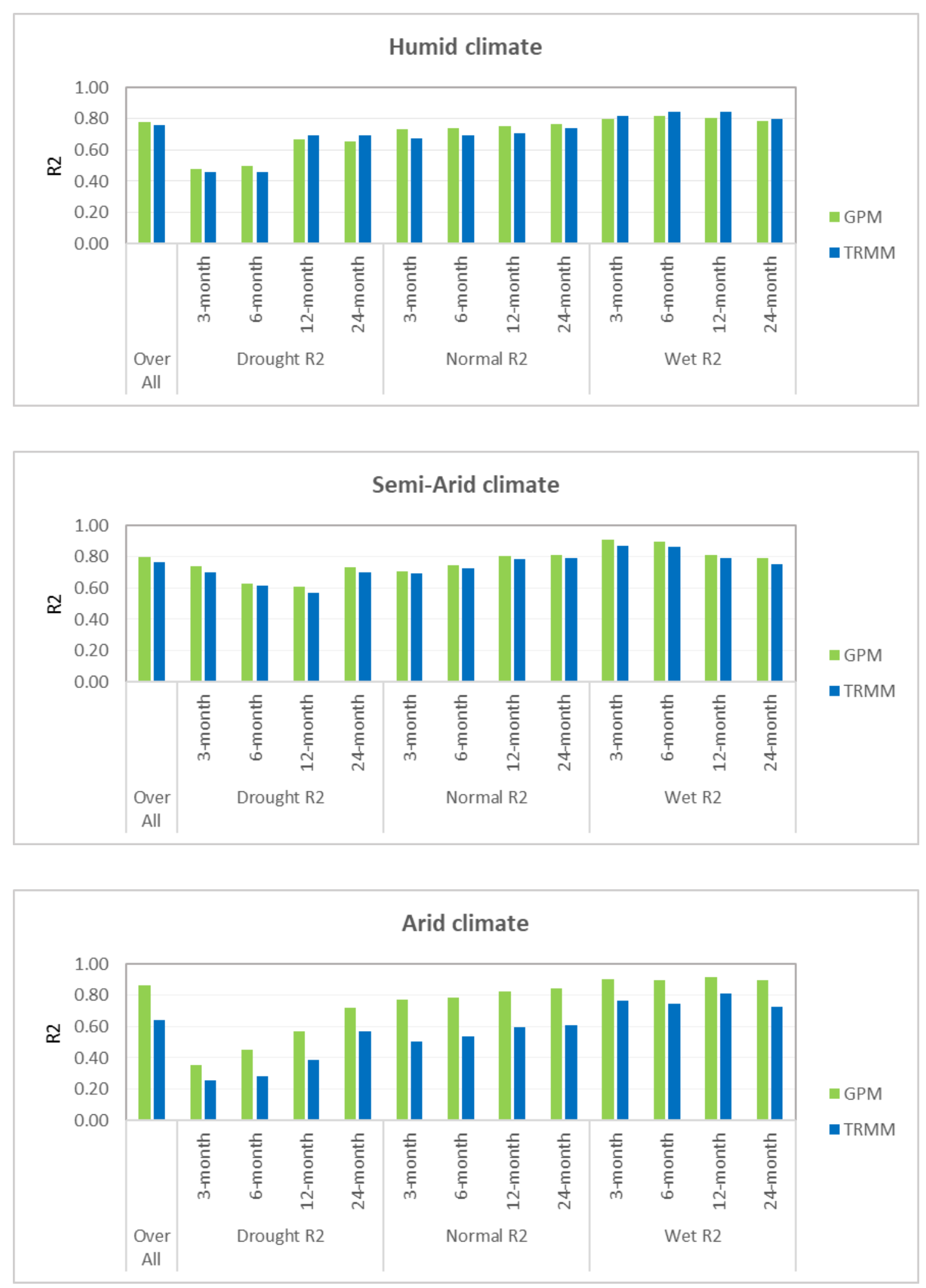

Figure 8: Comparison of average Accuracy of Satellite data in Wet, Normal and Drought periods

3.3. Seasonal accuracy of GPM and TRMM data in different climatic conditions The seasonal precipitation variation of satellites and stations of different 
climates is shown in Figure 9. There is a good agreement between GPM/TRMM and ground data. However, in the arid region, TRMM shows relatively large deviations from the average. In Figure 9, the yearly rainfalls are 75,15 , and 5 millimeters per month for high rain, semi-arid, and arid regions, respectively. The maximum and minimum amount of precipitation in different climatic zones happens in different seasons.

Ground
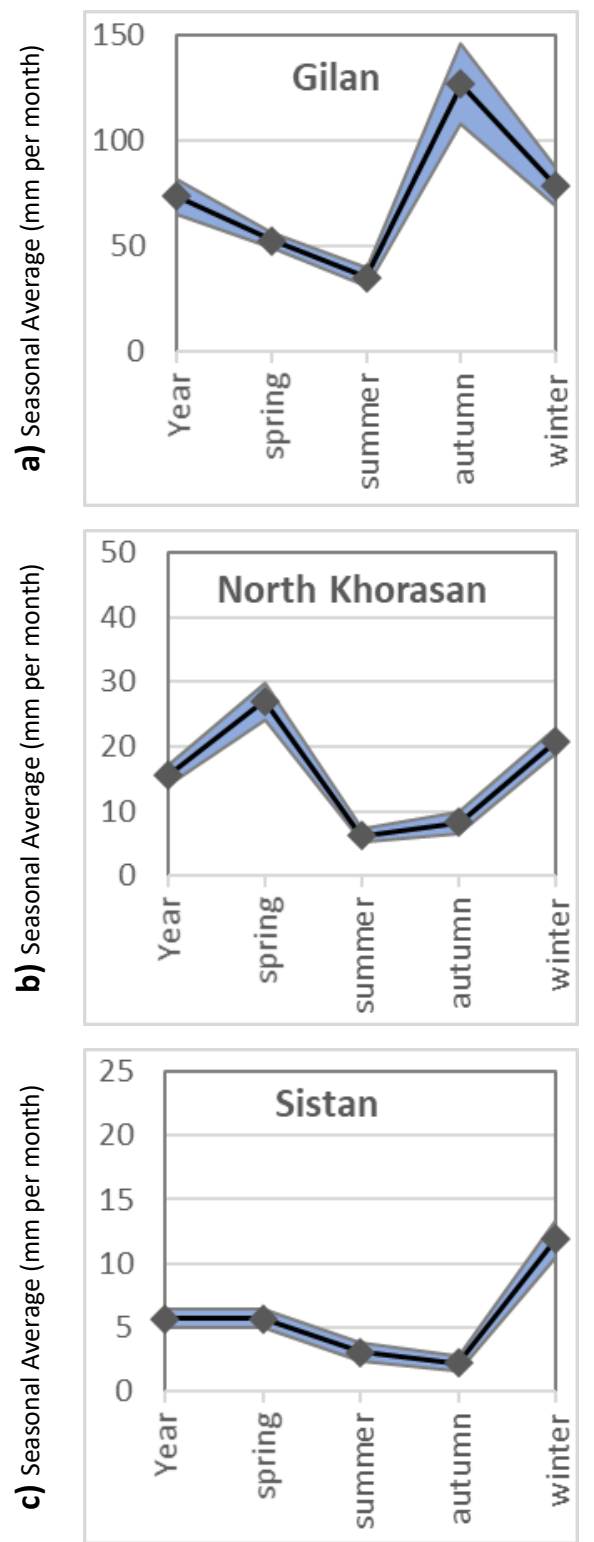

GPM
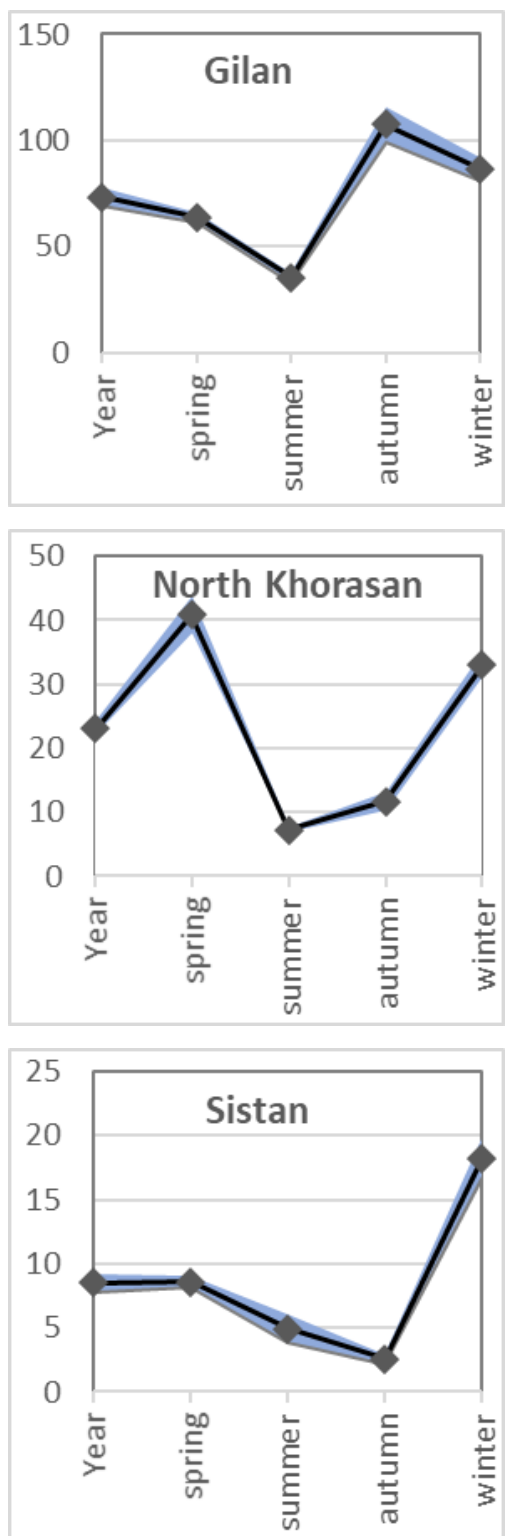

TRMM
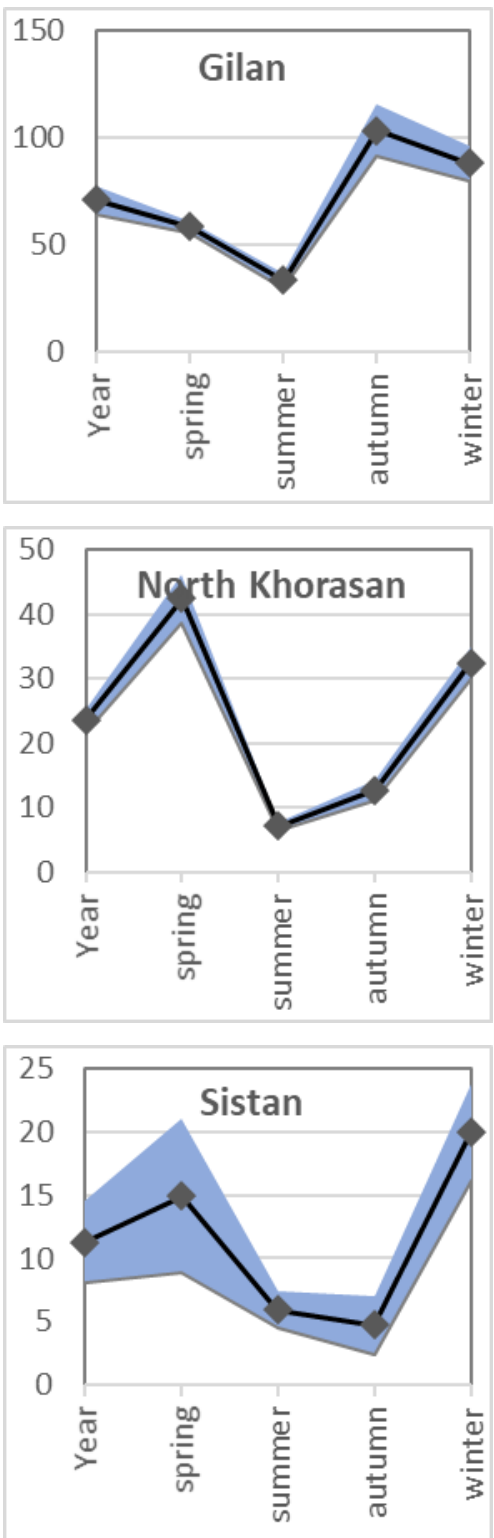

Figure 9. Comparison of the average of the station and satellite precipitation from 2000 to 2017 in study areas a) Humid and High Rain b) Semi-arid and Low Rain and c) Arid and Low Rain

Figure 10 also compares the accuracy and standard error of satellite data with ground measurements in different seasons. The accuracy of GPM is higher than TRMM over year measurement. In the arid area, GPM's accuracy is 0.8 , while TRMM's is 0.67 with a higher standard error (S.E.) than GPM The amounts of accuracies become 0.71 and 0.49 for GPM and TRMM during spring. For high rain and semi-arid region, the results have lower differences. 


\section{Seasonal Accuracy of GPM and TRMM over different Climates}

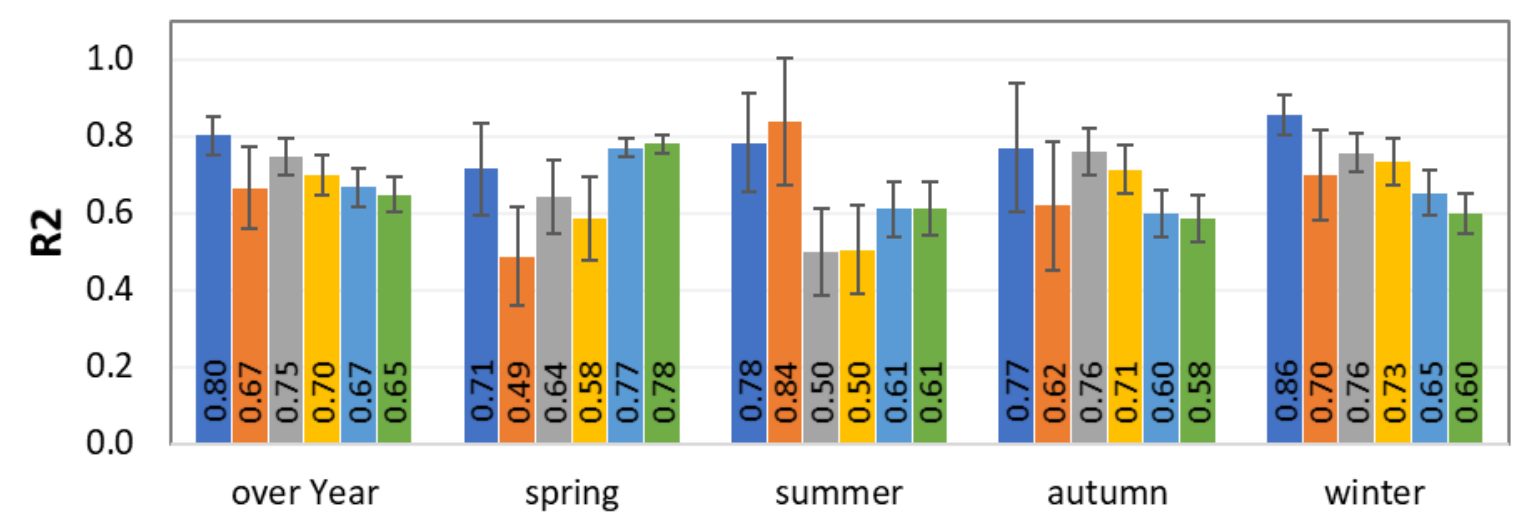

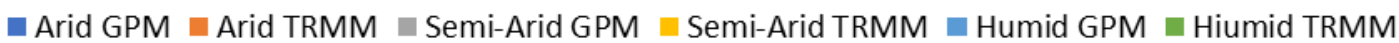

Figure 10. Average seasonal accuracy of GPM and TRMM data and their Standard Errors in the study areas

\subsection{Forecasting the correction factor based on the properties of ground synoptic stations}

Linear regression using the stepwise method showed that there are only three statistically significant independent variables. Therefore, the final regression equation is converted to equation 4 :

$$
X=\alpha_{0}+\alpha_{1} \text { Precipitation }+\alpha_{2} \text { Altitude }+\alpha_{3} \text { Latitude }
$$

The coefficients of equation 4 for GPM data are shown in Table 4 . The t-value shows that the mean precipitation effect is more than two times higher than the altitude and latitude effect on the correction factor and statistically significant based on the p-value.

Table 4. The results of a linear regression of the prediction accuracy of GPM data based on stations parameters

\begin{tabular}{cccccc}
\hline Parameter of stations & Coefficient & Std. Error & $\mathbf{t}$ & Sig. & V.I.F. \\
\hline (Constant) & 1.343 & 0.239 & 5.609 & 0.000 & \\
Latitude & -0.031 & 0.008 & -3.822 & 0.001 & 1.698 \\
Altitude & 0.00024 & 0.000 & 3.170 & 0.004 & 1.851 \\
Precipitation Mean & 0.242 & 0.032 & 7.470 & 0.000 & 2.716 \\
\hline
\end{tabular}

Also, the coefficients of equation 4 for TRMM data are shown in Table 5.

Table 5. The results of a linear regression of the prediction accuracy of TRMM data based on stations parameters

\begin{tabular}{cccccc}
\hline Parameter of stations & Coefficient & Std. Error & $\mathbf{t}$ & Sig. & V.I.F. \\
\hline (Constant) & 1.322 & 0.256 & 5.156 & 0.000 & \\
Latitude & -0.031 & 0.009 & -3.644 & 0.001 & 1.698 \\
\hline
\end{tabular}




\begin{tabular}{cccccc}
\hline Altitude & 0.00026 & 0.000 & 3.249 & 0.003 & 1.851 \\
Precipitation Mean & 0.246 & 0.035 & 7.085 & 0.000 & 2.716 \\
\hline
\end{tabular}

In Figure 11, the comparison of observed and predicted correction factors for GPM and TRMM data is shown. The $\mathrm{R}^{2}$ values are 0.71 and 0.68 for the prediction of GPM and TRMM precision, respectively.

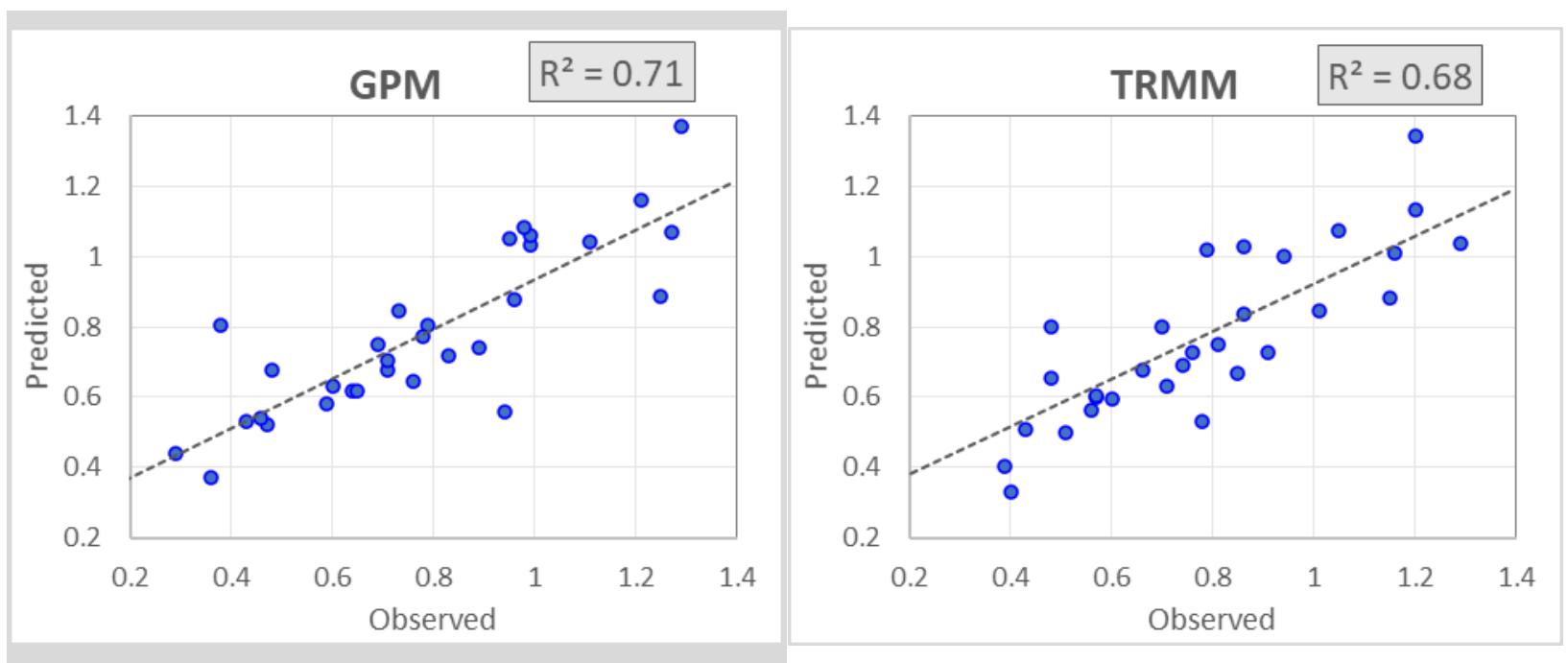

Figure 11. Comparison of the observed and predicted correction factors of GPM and TRMM; the correction factors are dimensionless

\section{Discussion}

Rainfall is the primary source of freshwater supply on the Earth's [55], and accurate and precise understanding of the amount of rain can help in various fields, such as agriculture and preventions of a natural disaster [56]. Satellite data is one of the essential sources of rainfall data due to its global coverage, broad time ranges, and low cost [57]. Various studies have shown that in some places, the accuracy of satellite data is not entirely reliable and requires error correction [58]. In this study, satellite data accuracy (GPM/TRMM) was evaluated in three different climates. Besides, winter rainfall plays a vital role in the growth of trees and preventing premature forest fires, so a more accurate estimate of rainfall in winter can be beneficial in forest management researches [51]. Therefore, the accuracy of the data should be checked in different seasons. Furthermore, drought and wet conditions are critical in water resources management. Consequently, the reliability of drought and wet conditions is essential and can be useful in increasing the accuracy of predictions and timely warnings.

The average temperatures in the synoptic stations of the rainy and humid zone are between 12 and 19 degrees Celsius, and the average relative humidities are between 59 and 83 percent. In the semi-arid area, the average temperatures are between 13 and 17 degrees, and the average humidities are between 43 and 60 percent. However, the mentioned variables have a broader range in the arid region. The average temperatures in this province are from 19 to 31, and the average relative humidities are between $18 \%$ and $74 \%$. Being close to the Sea of Oman has caused high relative humidity for nearby stations.

Authors should discuss the results and how they can be interpreted from the perspective of previous studies and of the working hypotheses. The findings and their im- 
plications should be discussed in the broadest context possible. Future research directions may also be highlighted.

\subsection{The comparison of GPM and TRMM accuracy and precision prediction}

GPM instrument has more advantages than TRMM; our investigations over different climates showed that the IMERG algorithm is mostly more accurate than the TMPA/3B43 algorithm, although, in some stations, TRMM is slightly (less than 5\%) better than GPM. The average accuracy of satellite data in the arid climate is better than in other climates. On average, the highest difference between GPM and TRMM data over various climates belongs to the arid climate and the lowest to the rainy climate. The highest difference between GPM and TRMM is for the station, namely ZAHAK, in the arid climate in which R2 of TRMM was 0.15 while it is 0.85 for GPM. In other words, the maximum improvement of IMERGS happened over the arid climatic condition.

The correction factor (C.F.) obtained by minimizing the RMSE between the ground station and satellite data has a different pattern in various climates. In the humid region, GPM/TRMM overestimated the rainfall amount; however, in the semi-arid and arid areas, satellite results underestimated the precipitation. The spatial analysis of C.F. shows that in the humid area, in locations exposed to sea with dense vegetation, the rainfall is overestimated by satellite; however, in stations behind the reliefs, precipitations were underestimated as same as semi-arid and arid climate.

Although the C.F. does not affect precipitation estimation accuracy between the stations and satellite data, it corrects monthly precipitation precision. In other words, GPM/TRMM overestimates and underestimates the rainfall, and C.F. adjusts the rainfall estimation to be near the station amount. Our investigations showed that C.F. could be predicted using average precipitation, altitude, and latitude of the locations. Average precipitation and altitude have positive, and latitude has a negative effect on the amount of C.F. In other words, GPM/TRMM overestimates the precipitation as the latitude increases. Also, for locations with high rain or high altitudes, GPM/TRMM underestimates the precipitation. The coefficients of the regression equation indicate that for a one-millimeter increase in mean rainfall, 0.242 , and 0.246 units are added to the correction factors of GPM and TRMM, respectively. However, the latitude has an inverse effect on the correction factors so that by increasing one degree in latitude, the correction factor reduces by 0.031 in both correction factors. Also, altitude increases the correction factors so that 1000 increase in altitude rise the factor 0.24 . The factor is unitless. The introduces C.F. only adjusts the precision of precipitation but does not affect the accuracy. The results show that not only the overall accuracy of GPM is higher than TRMM, but it is also more precise than TRMM.

\subsection{Accuracy of satellite data in drought, normal, and wet conditions}

Due to the importance of rainfall in drought periods and a positive correlation between the C.F. and the amount of rainfall, the accuracy was examined to measure satellite data's reliability in drought or wet conditions. Drought or wet periods are directly related to the time scale [47]. In other words, a region can be in drought condition on a time scale and wet at another time scale. In the short scale, drought means dry soil, but drying rivers leads to long-term drought. Therefore, in a region, the soil may be wet, but the rivers may be dry and vice versa [48]. S.P.I. can show drought or wet conditions at different time scales. Our results show that with increasing the time scales, the accuracy increases as well. In other words, satellite data have higher accuracy in predicting long-term drought or wet conditions, but for short-term periods should be used with caution.

The calculations were done only for the stations, which have at least 20 years because of the S.P.I. index limitation. Generally speaking, GPM data are always more accurate than TRMM in all drought conditions. However, it seems their data have different accuracies in different scales of droughts and conditions. In general, satellite data has the highest accuracy in wet conditions and the lowest accuracy in drought periods. Fur- 
thermore, Figure 8 shows that the GPM algorithm operates more accurately than in the arid region, especially in drought conditions. More importantly, satellite data accuracy in short-term drought conditions, especially in the arid climate, is significantly lower than normal and wet conditions. In drought conditions, the lowest accuracy belongs to the arid area in the short-term period. In other words, the monitoring of agricultural drought can have high uncertainty. As far as our research shows, many evaluations of drought or wet monitoring are based on satellite data, but our study shows that drought or wet monitoring through satellite data, especially for drought periods, should be done with caution [32, 59-63]. In the arid region, there are two stations with high relative humidity; however, our results show that the arid environment's relative humidity does not affect satellite data accuracy.

\subsection{Accuracy of satellite data in the seasons of a year}

In general, in the humid region, the highest rainfall occurs in autumn and the lowest in summer. However, in the semi-arid area, the highest rain in spring and lowest in summer-fall. The pattern of precipitation in arid location is totally different, and the highest and lowest rainfall occur in winter and autumn, respectively. During the seasons, there is a perfect agreement between the highest and lowest accuracy of GPM/TRMM and station. GPM/TRMM correctly estimates the patterns; however, TRMM has a considerable error in the arid region's spring season.

In humid and high rain areas, the most important accuracy occurs in spring, while in the arid, the lowest accuracy occurs in spring. In contrast, the arid region's largest accuracy happens in winter, but the humid region's minimum accuracy occurs in winter. The accuracy in the semi-arid study area is a transition of the humid area and arid area. The highest and lowest accuracies happen in autumn and summer in semi-arid, respectively.

Generally, over the year, GPM has the highest accuracy and lowest standard error in the arid climate. In contrast, TRMM has the lowest accuracy and highest standard error in the arid climate. Seasonal exploration of data accuracy shows that GPM has the best results during winter in the arid region, while in other seasons, it has slightly lower accuracy and larger standard error. On the other hand, TRMM has the best results in summer and worst in spring with high standard error. On average, in the studied areas, the highest accuracy and lowest scattering occurred in winter and spring. However, the most insufficient accuracy with the highest dispersion occurred in summer. These results are contrary to the findings of Kolios and Kalimeris [64] in the Mediterranean region.

The results of the seasonal accuracy assessment of satellite data show, on average, the accuracy of data decreases with warming the air and reaches the lowest value in the summer. The accuracy again decreases by increasing the air temperature. The accuracy of the data begins to increase in the autumn and reaches its maximum value in the winter. The standard error is the highest in summer and lowest in winter. These results are in complete agreement with the results of Adeyewa and Nakamura [21]. The overall average accuracy from highest to lowest is in winter, spring, autumn, and summer. A hypothesis is formed here in the study, which the low accuracy of satellite data in the summer, probably due to the rapid evaporation and short duration of precipitation in the regions. In other words, the satellite has measured precipitation that a part of which has evaporated before it reaches the ground station, so precipitation accuracy in hot weather is estimated to be lower than in cold weather.

In the end, the lack of long-term meteorological ground station data, the limited number of stations, and the non-uniform distribution of ground station distribution limited our study to explore the satellite data in depth. Therefore, more investigations with a larger number of ground stations and an extensive study area, especially for drought monitoring, are suggested for future studies. Also, the accuracy of precipitation after long drought conditions that leads to flood occurrence seems necessary for extra investigations.

\section{Conclusions}


Accurate precipitation data lead to accurate results in various agricultural applications, water resources management, and natural disasters. Despite the advantages of satellite precipitation data, there is a lack of accuracy in some parts of the world, the knowledge of which can lead to the discovery of correct results and reliable interpretations. In this paper, the accuracy of satellite data in three climates including, humid and rainy, semi-arid with low rainfall, and arid with low rainfall, in drought and wet conditions and different seasons, were examined. The results of this study are as follows. (1) In the study area, the precision of satellite data in different climates depends on latitude, so that in high latitudes, GPM/TRMM overestimates the precipitation data and vice versa. (2) The average monthly rainfall measured by satellite in the high rainfall region is $11 \%$, in the semi-arid $50 \%$, and the arid area $43 \%$ more than station measurements. (3) The introduced correction factor (C.F.) does not affect the value of the $\mathrm{R}^{2}$ coefficient. C.F. increases the precision of the satellite data. (3) $71 \%$ and $68 \%$ of the variation of GPM and TRMM CFs can be explained by three parameters, including mean precipitation, altitude, and latitude. (4) The accuracy of satellite data in wet conditions is higher than the normal conditions, and the accuracy in normal conditions is more than the accuracy in drought conditions. The lowest accuracy occurs in the drought condition of the arid region. (5) Satellite data have the highest accuracy in winter and the lowest accuracy in summer.

Author Contributions: Conceptualization, J.K., A.A.K. and S.Q.; Formal analysis, S.Q., A.A.K., J.K., and S.Q.; Funding acquisition, S.Q.; Investigation, J.K., S.Q. and A.A.K.; Methodology, J.K. and S.Q.; Project administration, A.A.K.; Software, J.K. and S.Q.; Supervision, S.Q., and A.A.K.; Visualization, J.K. and S.Q.; Writing-original draft, J.K. and S.Q.; Writing-review \& editing, S.Q., M.K.F., and A.A.K. All authors have read and agreed to the published version of the manuscript.

Funding: This research received no external funding.

Informed Consent Statement: Not applicable.

Data Availability Statement: Data are available in request.

Conflicts of Interest: The authors declare no conflict of interest.

\section{References}

1. Shukla, A.K., et al., Evaluation of TRMM Precipitation Dataset over Himalayan Catchment: The Upper Ganga Basin, India. Water, 2019. 11(3): p. 613.

2. Ebert, E.E., J.E. Janowiak, and C. Kidd, Comparison of near-real-time precipitation estimates from satellite observations and numerical models. Bulletin of the American Meteorological Society, 2007. 88(1): p. 47-64.

3. Faurès, J.-M., et al., Impact of small-scale spatial rainfall variability on runoff modeling. Journal of hydrology, 1995. 173(1-4): p. 309-326.

4. Yan, Y., et al., Climatology and Interannual Variability of Floods During the TRMM Era (1998-2013). Journal of Climate, 2020(2020).

5. Robbins, J., A probabilistic approach for assessing landslide-triggering event rainfall in Papua New Guinea, using TRMM satellite precipitation estimates. Journal of Hydrology, 2016. 541: p. 296-309.

6. Ibadullah, W.M.W., et al., Practical Predictability of the 17 December 2014 Heavy Rainfall Event over East Coast of Peninsular Malaysia using W.R.F. Model. Sains Malaysiana, 2019. 48(11): p. 2297-2306.

7. Amini, A., et al., Application of TRMM Precipitation Data to Evaluate Drought and Its Effects on Water Resources Instability. Applied Sciences, 2019. 9(24): p. 5377.

8. Du, L., et al., A comprehensive drought monitoring method integrating MODIS and TRMM data. International Journal of Applied Earth Observation and Geoinformation, 2013. 23: p. 245-253.

9. Collischonn, B., W. Collischonn, and C.E.M. Tucci, Daily hydrological modeling in the Amazon basin using TRMM rainfall estimates. Journal of Hydrology, 2008. 360(1-4): p. 207-216.

10. TURK, F.J., et al., Meteorological applications of precipitation estimation from combined SSM/I, TRMM and infrared geostationary. Microwave Radiometry and Remote Sensing of the Earth's Surface and Atmosphere, 2000: p. 353.

11. Macharia, J.M., F.K. Ngetich, and C.A. Shisanya, Comparison of satellite remote sensing derived precipitation estimates and observed data in Kenya. Agricultural and Forest Meteorology, 2020. 284: p. 107875.

12. Zipper, S.C. and S.P. Loheide II, Using evapotranspiration to assess drought sensitivity on a subfield scale with HRMET, a high resolution surface energy balance model. Agricultural and Forest Meteorology, 2014. 197: p. 91-102.

13. Lu, X., et al., The Development of a Two-Step Merging and Downscaling Method for Satellite Precipitation Products. Remote Sensing, 2020. 12(3): p. 398. 
14. AghaKouchak, A., et al., Evaluation of satellite-retrieved extreme precipitation rates across the central United States. Journal of Geophysical Research: Atmospheres, 2011. 116(D2).

15. Chen, Y., et al. Evaluation of TRMM Daily Precipitation Estimates of Tropical Cyclone Rainfall using PACRAIN Data. in AGU Fall Meeting Abstracts. 2012.

16. Kidd, C., et al., Satellite rainfall estimation using combined passive microwave and infrared algorithms. Journal of Hydrometeorology, 2003. 4(6): p. 1088-1104.

17. Xie, P. and P.A. Arkin, Global precipitation: A 17-year monthly analysis based on gauge observations, satellite estimates, and numerical model outputs. Bulletin of the American Meteorological Society, 1997. 78(11): p. 2539-2558.

18. Smith, M., The application of climatic data for planning and management of sustainable rainfed and irrigated crop production. Agricultural and Forest Meteorology, 2000. 103(1-2): p. 99-108.

19. Seed, A. and G. Austin, Variability of summer Florida rainfall and its significance for the estimation of rainfall by gages, radar, and satellite. Journal of Geophysical Research: Atmospheres, 1990. 95(D3): p. 2207-2215.

20. Michaelides, S., et al., Precipitation: Measurement, remote sensing, climatology and modeling. Atmospheric Research, 2009. 94(4): p. 512-533.

21. Adeyewa, Z.D. and K. Nakamura, Validation of TRMM radar rainfall data over major climatic regions in Africa. Journal of Applied Meteorology, 2003. 42(2): p. 331-347.

22. McKee, T.B., N.J. Doesken, and J. Kleist. The relationship of drought frequency and duration to time scales. in Proceedings of the 8th Conference on Applied Climatology. 1993. Boston.

23. Zhou, Z., et al., Multidimensional evaluation of the TRMM 3B43V7 satellite-based precipitation product in mainland China from 1998-2016. PeerJ, 2020. 8: p. e8615.

24. Dai, A., Drought under global warming: a review. Wiley Interdisciplinary Reviews: Climate Change, 2011. 2(1): p. 45-65.

25. Tan, M.L., et al., Evaluation of TRMM product for monitoring drought in the Kelantan River Basin, Malaysia. Water, 2017. 9(1): p. 57.

26. Vicente-Serrano, S.M., et al., A new global 0.5 gridded dataset (1901-2006) of a multiscalar drought index: comparison with current drought index datasets based on the Palmer Drought Severity Index. Journal of Hydrometeorology, 2010. 11(4): p. 1033-1043.

27. Morid, S., V. Smakhtin, and M. Moghaddasi, Comparison of seven meteorological indices for drought monitoring in Iran. International Journal of Climatology: A Journal of the Royal Meteorological Society, 2006. 26(7): p. 971-985.

28. Akhtari, R., et al., Assessment of areal interpolation methods for spatial analysis of S.P.I. and E.D.I. drought indices. International Journal of Climatology: A Journal of the Royal Meteorological Society, 2009. 29(1): p. 135-145.

29. Tabari, H., H. Abghari, and P. Hosseinzadeh Talaee, Temporal trends and spatial characteristics of drought and rainfall in arid and semi-arid regions of Iran. Hydrological Processes, 2012. 26(22): p. 3351-3361.

30. Rostamian, R., S. Eslamian, and M.R. Farzaneh, Application of standardised precipitation index for predicting meteorological drought intensity in Beheshtabad watershed, central Iran. International Journal of Hydrology Science and Technology, 2013. 3(1): p. 63-76.

31. SafarianZengir, V., B. Sobhani, and S. Asghari, Modeling and Monitoring of Drought for forecasting it, to Reduce Natural hazards Atmosphere in western and north western part of Iran, Iran. Air Quality, Atmosphere \& Health, 2020. 13(1): p. 119-130.

32. Nastos, P., J. Kapsomenakis, and K. Philandras, Evaluation of the TRMM 3B43 gridded precipitation estimates over Greece. Atmospheric Research, 2016. 169: p. 497-514.

33. Darand, M., J. Amanollahi, and S. Zandkarimi, Evaluation of the performance of TRMM Multi-satellite Precipitation Analysis (TMPA) estimation over Iran. Atmospheric Research, 2017. 190: p. 121-127.

34. Wang, N., et al., Evaluating satellite-based and reanalysis precipitation datasets with gauge-observed data and hydrological modeling in the Xihe River Basin, China. Atmospheric Research, 2020. 234: p. 104746.

35. Sharifi, E., R. Steinacker, and B. Saghafian, Assessment of GPM-IMERG and other precipitation products against gauge data under different topographic and climatic conditions in Iran: Preliminary results. Remote Sensing, 2016. 8(2): p. 135.

36. Maghsood, F.F., et al., Ground Validation of GPM IMERG Precipitation Products over Iran. Remote Sensing, $2020.12(1)$ : p. 48.

37. Zeng, H., L. Li, and J. Li, The evaluation of TRMM Multisatellite Precipitation Analysis (TMPA) in drought monitoring in the Lancang River Basin. Journal of Geographical Sciences, 2012. 22(2): p. 273-282.

38. Tan, M.L., et al., Evaluation of TMPA $3 \mathrm{~B} 43$ and NCEP-CFSR precipitation products in drought monitoring over Singapore. International journal of remote sensing, 2018. 39(8): p. 2089-2104.

39. Xu, F., et al., Systematical evaluation of GPM IMERG and TRMM 3B42V7 precipitation products in the Huang-Huai-Hai Plain, China. Remote Sensing, 2019. 11(6): p. 697.

40. TAJBAKHSH, S., et al., Assessment and Calibration of Gilan Radar Precipitation intensity using ground station data. JOURNAL OF THE EARTH AND SPACE PHYSICS, 2018. 44(3 \#a00411): p. - .

41. FAHIMI NEZHD, E., et al., SYNOPTIC-SPATIAL ANALYSIS OF A SNOWSTORM IN GILAN, FEBRUARY 2005. JOURNAL OF GEOGRAPHY AND REGIONAL DEVELOPMENT, 2013. -(19): p. -.

42. GHAZANFARI MOGHADDAM, M.S., et al., COMPARISON THE PERSIANN MODEL WITH THE INTERPOLATION METHOD TO ESTIMATE DAILY PRECIPITATION (A CASE STUDY: NORTH KHORASAN). JOURNAL OF WATER AND SOIL (AGRICULTURAL SCIENCES AND TECHNOLOGY), 2011. 25(1): p. - .

43. REZAEI PAZHAND, H. and B. GHAHRAMAN, ESTIMATING MAXIMUM DAILY PRECIPITATION BY MULTI-STATION METHOD: A CASE STUDY OF NORTH KHORASAN. IRAN-WATER RESOURCES RESEARCH, 2006. 2(1 (4)): p. -. 
44. RAHIMI, D., S. MOVAHDI, and H. BARGHI, ASSESSMENT OF DROUGHT SEVERITY USING NORMAL PRECIPITATION INDEX (CASE STUDY SISTAN AND BALUCHESTAN PROVINCE ). GEOGRAPHY AND ENVIRONMENTAL PLANNING (UNIVERSITY OF ISFAHAN), 2010. 20(4 (36)): p. -.

45. KHAKSAFIDI, A., et al., RAINFALL TEMPORAL DISTRIBUTION PATTERNS IN SISTAN \& BALOUCHESTAN PROVINCE (IRAN). JOURNAL OF WATER AND SOIL CONSERVATION (JOURNAL OF AGRICULTURAL SCIENCES AND NATURAL RESOURCES), 2010. 17(1): p. -.

46. Rhee, J., J. Im, and G.J. Carbone, Monitoring agricultural drought for arid and humid regions using multi-sensor remote sensing data. Remote Sensing of Environment, 2010. 114(12): p. 2875-2887.

47. Guttman, N.B., Accepting the standardized precipitation index: a calculation algorithm 1. JAWRA Journal of the American Water Resources Association, 1999. 35(2): p. 311-322.

48. Belayneh, A., et al., Long-term S.P.I. drought forecasting in the Awash River Basin in Ethiopia using wavelet neural network and wavelet support vector regression models. Journal of Hydrology, 2014. 508: p. 418-429.

49. Mishra, A. and V. Desai, Drought forecasting using feed-forward recursive neural network. ecological modelling, 2006. 198(1-2): p. 127-138.

50. Rittenhouse, C.D. and A.R. Rissman, Changes in winter conditions impact forest management in north temperate forests. Journal of environmental management, 2015. 149: p. 157-167.

51. Westerling, A.L., et al., Climate, Santa Ana winds and autumn wildfires in southern California. Eos, Transactions American Geophysical Union, 2004. 85(31): p. 289-296.

52. Zhou, T., et al., Summer precipitation frequency, intensity, and diurnal cycle over China: A comparison of satellite data with rain gauge observations. Journal of Climate, 2008. 21(16): p. 3997-4010.

53. Campbell, D. and S. Campbell. Introduction to regression and data analysis. in StatLab Workshop Series. 2008.

54. Christoffersen, P., Elements of financial risk management. 2012: Academic Press.

55. Sharma, A., Seasonal to interannual rainfall probabilistic forecasts for improved water supply management: Part $1-$ A strategy for system predictor identification. Journal of Hydrology, 2000. 239(1-4): p. 232-239.

56. Hou, A.Y., et al., The global precipitation measurement mission. Bulletin of the American Meteorological Society, 2014. 95(5): p. 701-722.

57. Vernimmen, R., et al., Evaluation and bias correction of satellite rainfall data for drought monitoring in Indonesia. 2012.

58. Kenabatho, P., B. Parida, and D. Moalafhi, Evaluation of satellite and simulated rainfall products for hydrological applications in the Notwane Catchment, Botswana. Physics and Chemistry of the Earth, Parts A/B/C, 2017. 100: p. 19-30.

59. Cashion, J., et al., Microwave remote sensing of soil moisture: evaluation of the TRMM microwave imager (T.M.I.) satellite for the Little River Watershed Tifton, Georgia. Journal of hydrology, 2005. 307(1-4): p. 242-253.

60. Wang, J. and D.B. Wolff, Evaluation of TRMM ground-validation radar-rain errors using rain gauge measurements. Journal of Applied Meteorology and Climatology, 2010. 49(2): p. 310-324.

61. Chen, S., et al., Evaluation of the successive V6 and V7 TRMM multisatellite precipitation analysis over the Continental United States. Water Resources Research, 2013. 49(12): p. 8174-8186.

62. Cao, Y., W. Zhang, and W. Wang, Evaluation of TRMM 3B43 data over the Yangtze River Delta of China. Scientific reports, 2018. 8(1): p. 1-12.

63. Li, R., et al., Evaluation and Hydrological Application of TRMM and GPM Precipitation Products in a Tropical Monsoon Basin of Thailand. Water, 2019. 11(4): p. 818.

64. Kolios, S. and A. Kalimeris, Evaluation of the TRMM rainfall product accuracy over the central Mediterranean during a 20-year period (1998-2017). Theoretical and Applied Climatology, 2020. 139(1-2): p. 785-799. 